\title{
Aberrant expression of $\beta$-catenin, Pin 1 and cylin D1 in salivary adenoid cystic carcinoma: Relation to tumor proliferation and metastasis
}

\author{
CHUAN-XIANG ZHOU and YAN GAO
}

Department of Oral Pathology, Peking University School of Stomatology, 22 South Ave. Zhong-Guancun, Hai-Dian District, Beijing, P.R. China

Received March 23, 2006; Accepted May 22, 2006

\begin{abstract}
The aims of this study were to investigate the expression levels of ß-catenin, Pin 1 and cyclin D1 in salivary adenoid cystic carcinomas (SACC) and to evaluate its clinical importance, furthermore, to elucidate whether $\beta$-catenin expression was aberrant in SACC and whether Pin 1 was involved in aberrant $\beta$-catenin and cyclin D1 expression. The expression of Pin1, $\beta$-catenin and cyclin D1 were examined in the specimens of 65 patients with SACC by immunohistochemistry, protein and mRNA expressions were detected by Western blotting and RT-PCR in four SACC cell lines. Pin 1 was overexpressed in 51 cases of SACC (78\%), and high levels of Pin 1 expression correlated with cyclin D1 positive expression $(\mathrm{p}=0.02)$. Fourteen $(22 \%)$ cases showed positive immunoreactivity for $\beta$-catenin protein in the nuclear/cytoplasmic fraction in tumor tissues, which was defined as cytoplasm/nucleus staining, among which quite evident nuclear expression of $\beta$-catenin was detected in six cases (9\%), while cyclin D1 positive expression was detected in 41 cases of SACC (63\%). Reduced membranous expression of $\beta$-catenin was detected in the cases with metastasis $(11 / 14)$. Theses results suggest that Pin 1 and Wnt signalling pathway are activated in SACC and may play a pivotal role in SACC carcinogenesis and metastasis.
\end{abstract}

\section{Introduction}

Salivary adenoid cystic carcinoma (SACC) is a relatively commonly seen salivary gland tumor with high invasive nature, readily nerve and vascular involvement and high metastatic rate through circulation. Clinically, it usually arises in middle-

Correspondence to: Dr Yan Gao, Department of Oral Pathology, Peking University School of Stomatology, 22 South Ave. ZhongGuancun, Hai-Dian District, Beijing, P.R. China

E-mail: gaoyan0988@263.net zhoucx2008@126.com

Key words: Pin1, ß-catenin, cyclin D1, immunohistochemistry, Western blot, RT-PCR, salivary adenoid cystic carcinomas aged or elderly patients, generally presenting as slow-growing but highly malignant neoplasm with extremely poor long-term prognosis and remarkable capacity for recurrence. Histologically, it is classified into tubular, cribriform and solid types, and the general consensus is that SACC with tubular or cribriform subtype have a better prognosis than those with solid subtype (1).

Wnts are powerful regulators of cell proliferation and differentiation, and their signaling pathway involves proteins that directly participate in both gene transcription and cell adhesion (2). The central player is B-catenin, which is a transcription cofactor with $\mathrm{T}$ cell factor/lymphoid enhancer factor (TCF/LEF) in the Wnt pathway (3). B-catenin accumulation in a complex with the transcription factor TCF/LEF can regulate target gene expression, for example, cyclin D1, a critical cellcycle regulator that drives the cell cycle from the G1 to the $\mathrm{S}$ phase (4). Cyclin D1 elevation in transformed cells may result from a direct activation of cyclin D1 transcription by the $\beta$-catenin/LEF-1 complex.

As currently understood, $B$-catenin is negatively regulated by the tumor suppressor adenomatous polyposis coli (APC), which shuttles nuclear $\beta$-catenin to the cytoplasm and promotes its degradation. In some tumors, notably colon cancer, $B$-catenin is activated by mutations in the genes encoding APC or $\beta$ catenin (5-9). However, $\beta$-catenin is up-regulated in many other cancers, such as breast cancer, where mutations are rarely observed $(10,11)$. Therefore, epigenetic factors might contribute to $ß$-catenin activation. One such factor is the overexpression of Pin1, which is observed in many types of cancers such as breast, prostate and hepatocellular carcinoma (12-15). Pin1, a peptidyl-prolyl cis-trans isomerase (PPIase) that isomerizes only phosphorylated serine/threonine residues preceding proline peptide bonds in a defined subset of proteins, can specifically bind to the pSer246-Pro motif of $\beta$-catenin and inhibit its binding to APC, resulting in the nuclear accumulation and stabilization of B-catenin. Pin 1 can also bind to the pSer63- and/or pser73-Pro motifs in c-Jun, increasing the ability of c-Jun to activate the promoter of cyclin D1 (16). The aims of this study were to investigate the expression levels of Pin1, $\beta$-catenin and cyclin D1 in SACC and to evaluate its clinical importance, moreover, to elucidate whether B-catenin expression was aberrant in SACC and whether Pin1 was involved in aberrant B-catenin and cyclin D1 overexpression. We found that although membranous expressions of $\beta$-catenin were found 
Table I. Correlations between Pin1, cyclin D1, ß-catenin levels and clinicopathological parameters of SACC.

\begin{tabular}{|c|c|c|c|c|c|c|c|c|c|c|c|c|}
\hline \multirow[b]{3}{*}{ Total no. } & \multicolumn{5}{|c|}{ ß-catenin staining } & \multicolumn{4}{|c|}{ Cyclin D1 staining } & \multicolumn{3}{|c|}{ Pin1 staining } \\
\hline & \multirow{2}{*}{$\begin{array}{c}\text { No. } \\
65\end{array}$} & \multirow{2}{*}{$\frac{\mathrm{C} / \mathrm{N}(\%)^{\mathrm{a}}}{14(22)}$} & \multicolumn{2}{|c|}{$\mathrm{M}(\%)^{\mathrm{b}}$} & \multirow[t]{2}{*}{ P-value } & \multicolumn{2}{|c|}{$(+)(\%)$} & \multirow{2}{*}{$\frac{(-)(\%)}{24(37)}$} & \multirow[t]{2}{*}{ P-value } & \multirow{2}{*}{$\begin{array}{c}\text { High }(\%) \\
51(78)\end{array}$} & \multirow{2}{*}{$\begin{array}{c}\text { Low }(\%) \\
14(22)\end{array}$} & \multirow[t]{2}{*}{ P-value } \\
\hline & & & 51 & $(78)$ & & 41 & (63) & & & & & \\
\hline \multicolumn{13}{|l|}{ Gender } \\
\hline Male & 24 & $6(25)$ & 18 & $(75)$ & 0.60 & 17 & (71) & $7(29)$ & 0.32 & $16(67)$ & $8(33)$ & 0.07 \\
\hline Female & 41 & $8(19)$ & 33 & $(81)$ & & 24 & $(59)$ & $17(41)$ & & $35(85)$ & $6(15)$ & \\
\hline \multicolumn{13}{|l|}{ Location } \\
\hline Parotid gland & 19 & $6(32)$ & 13 & $(68)$ & & 9 & $(47)$ & $10(53)$ & & $11(58)$ & $8(42)$ & \\
\hline Submandibular gland & 11 & $4(36)$ & 7 & $(64)$ & & 8 & (73) & $3(27)$ & & $10(91)$ & $1 \quad(9)$ & \\
\hline Sublingual gland & 18 & $1 \quad(6)$ & 17 & (94) & & 7 & (39) & $11(61)$ & & $15(83)$ & $3(17)$ & \\
\hline Palatine gland & 17 & $3(18)$ & 14 & $(91)$ & & 17 & $(100)$ & $0 \quad(0)$ & & $15(88)$ & $2(12)$ & \\
\hline \multicolumn{13}{|l|}{ Types } \\
\hline Tubular-Cribriform & 54 & $10(19)$ & 44 & $(81)$ & 0.36 & 32 & $(59)$ & $22(41)$ & 0.28 & $43(80)$ & $11(20)$ & 0.92 \\
\hline Solid type & 11 & $4(36)$ & 7 & (64) & & 9 & $(82)$ & $2(18)$ & & $8(73)$ & $3(27)$ & \\
\hline \multicolumn{13}{|l|}{ Tumor stage } \\
\hline $\mathrm{T} 1+\mathrm{T} 2$ & 46 & $11(24)$ & 35 & (76) & 0.69 & 27 & (59) & $19(41)$ & 0.26 & $34(74)$ & $12(26)$ & 0.29 \\
\hline $\mathrm{T} 3+\mathrm{T} 4$ & 19 & $3(16)$ & 16 & (84) & & 14 & (74) & $5(26)$ & & $17(89)$ & $2(11)$ & \\
\hline \multicolumn{13}{|l|}{ Nodal stage } \\
\hline No & 51 & $8(16)$ & 43 & (84) & 0.07 & 29 & (57) & $22(43)$ & 0.21 & $42(82)$ & $9(18)$ & 0.28 \\
\hline $\mathrm{N} 1-3$ & 14 & $6(43)$ & 8 & $(57)$ & & 12 & $(86)$ & $2(14)$ & & $9(64)$ & $5(36)$ & \\
\hline \multicolumn{13}{|l|}{ Metastasis } \\
\hline M0 & 59 & $14(24)$ & 45 & $(76)$ & 0.68 & 36 & $(61)$ & $23(39)$ & 0.53 & $46(78)$ & 13 (22) & 1.00 \\
\hline M1-3 & 6 & $0 \quad(0)$ & & (100) & & 5 & $(83)$ & $1(17)$ & & $5(83)$ & $1(17)$ & \\
\hline Nerve invasion & 49 & $14(29)$ & 35 & $(71)$ & & 40 & $(82)$ & $9(18)$ & & $39(79)$ & $10(21)$ & \\
\hline Recurrence & 24 & $6(25)$ & 18 & $(75)$ & & 17 & (71) & $7(29)$ & & $19(79)$ & $5(21)$ & \\
\hline
\end{tabular}

${ }^{\mathrm{a}} \mathrm{C} / \mathrm{N}$, cytoplasmic and nuclear expression of $\beta$-catenin; ${ }^{\mathrm{b}} \mathrm{M}$, membranous expression of $\beta$-catenin.

ubiquitously in the tumor cells in any subtype, nuclear expression of B-catenin in tumor cells was obvious in some cases, which might be regarded as an indication for activated, oncogenic, Wnt signaling and B-catenin/TCF transcription in SACC. On the other hand, reduced membranous expression of $\beta$-catenin was found in most of the patients with metastasis and decreased membranous expression of $B$-catenin significantly correlated with nodal metastasis in SACC. In additon, a high prevalence of Pin 1 and cyclin D1 overexpression was also detected in SACC and there was a significant association between Pin 1 and cyclin D1 expression.

\section{Materials and methods}

Patients and samples. Formalin-fixed paraffin-embedded blocks from 65 cases of salivary gland adenoid cystic carcinoma were retrieved from the file of the Department of Oral Pathology, Peking University School of Stomatology during 2000-2005. All specimens were obtained from either incisional biopsies or surgical excision of the lesions. None of the patients had received irradiation or chemotherapy before surgery. The clinical and pathological characteristics of these patients are summarized in Table I. The age range of the patients was 24-72 years, and the mean age was 41.3 years. Tumor stage and nodal metastasis stage were classified according to the fifth edition of the TNM Classification of the International Union Against Cancer (UICC). Histopathological diagnosis was made routinely at the Department of Oral Pathology, Peking University School of Stomatology. In addition, five tissues of normal salivary glands were also studied as control.

Cell culture. Four human salivary gland adenoid cystic carcinoma cell lines, SACC83, SACC-LM, ACC-2 and ACC-M, were kindly provided by surgery laboratory of Peking University School of Stomatology. The SACC83 and ACC-2 cell lines were originally established from human sublingual gland and palate gland adenoid cystic carcinoma respectively, while ACC-M, SACC-LM are highly lung metastatic salivary gland adenoid cystic carcinoma cell lines selected from ACC-2 and SACC83, respectively. All the cell 
lines were cultured in RPMI-1640 medium containing $15 \%$ fetal bovine serum and antibiotics (Hyclone, USA); growing at $37^{\circ} \mathrm{C}$ in a $5 \% \mathrm{CO}_{2}-95 \%$ air environment.

Immunohistochemistry. Formalin-fixed and paraffin-embedded SACC specimens were cut into $5-\mu \mathrm{m}$ thick sections, mounted on poly-L-Lysine coated slides, deparaffinised in xylene and rehydrated through a graded ethanol series. To quench endogenous peroxidase, sections were incubated with fresh $3 \%$ $\mathrm{H}_{2} \mathrm{O}_{2}$ in methanol for $30 \mathrm{~min}$ at room temperature, and then antigen retrieval was performed by microwave treatment for $20 \mathrm{~min}$ in $0.01 \mathrm{M}$ citrate buffer ( $\mathrm{pH}$ 6.0). After washing thrice in PBS, sections were pre-incubated with goat serum for $30 \mathrm{~min}$ at room temperature to prevent non-specific protein binding. Sections were incubated overnight at $4^{\circ} \mathrm{C}$ in a moist chamber with primary antibodies: rabbit polyclonal anti-Pin1, purchased from Oncogene Research Products (San Diego, CA, USA) and diluted 1:100; mouse monoclonal anti-ß-catenin and anticyclin D1, purchased from Zymed Laboratories Inc. (San Francisco, USA) and diluted 1:200. Sections were biotinylated with goat anti-mouse or goat anti-rabbit immunoglobin for $30 \mathrm{~min}$ at room temperature following washing thrice in PBS again. Staining was performed with a strepavidin-biotin peroxidase kit (Histotain-Bulk-SP kit, Zymed), and sites of bound of antibody were visualized using liquid DAB + substrate + chromogen system. Sections were lightly counterstained with Mayer's haematoxylin and mounted.

Evaluation of immunohistochemical results. The immunoreactivity of cyclin D1 protein staining was scored according to the percentage of positively stained tumor cell nuclei. According to previous studies, score was ranked as: negative, tumor cells were stained $<10 \%$; positive, when over $10 \%$ of tumor cells were positive. In this study, the staining pattern of $\beta$-catenin was scored according to previous studies. Score was ranked as: 3 , strong staining in a normal distribution; 2 , patchy or heterogeneous staining; 1 , weak and fragmented staining; 0, extremely weak or loss of staining. In addition, a score of 4 was used to indicate accumulation in the nuclear/ cytoplasmic fraction in tumor tissues. Then, according to the localization of ß-catenin staining, cytoplasm/nucleus staining was defined as score 4 , and membrane staining was defined as score $0,1,2$ and 3. The immunoreactivity of Pin1 was scored according to the staining intensity in the nucleus of tumor cells $(1$, weak; 2 , moderate; 3 , strong and intense staining in the nuclear and/or cytoplasm) and percent distribution. In normal salivary gland cells, the staining intensity in the nucleus was weak and moderate. Therefore, high level of Pin1 staining was defined as strong and intense (score 3) immunohistochemical staining, and low level of Pin1 as weak (score 1) and moderate (score 2) staining.

Western blot analysis. The four SACC cell lines were used to detect the Pin 1 and $\beta$-catenin expression by immunoblotting. Briefly, protein extraction were performed from lysates of exponentially growing cell lines with Pro-PREP ${ }^{\mathrm{TM}}$ Protein Extraction Kit (iNtRON Biotechnology), which contains five kinds of protease inhibitors such as PMSF, EDTA, pepstatin A, leupeptin and aprotinin. The protein concentration was determined with a BCA Protein Assay Kit (Pierce, USA). In all,
$60 \mu \mathrm{g}$ of protein from each cell line was resuspended in sodium dodecyl sulphate (SDS) sample buffer (100 mM Tris- $\mathrm{HCl}$, $\mathrm{pH} 8.8 ; 0.01 \%$ bromophenol blue; $36 \%$ glycerol; $4 \%$ SDS) containing $1 \mathrm{mM}$ dithiothreitol, boiled for $5 \mathrm{~min}$, and subjected to $15 \%(\mathrm{w} / \mathrm{v})$ SDS-PAGE and transferred onto nitrocellulose membrane (Bio-Rad Laboratories, USA). Non-specific reactivity was blocked by incubation overnight at $4{ }^{\circ} \mathrm{C}$ in $5 \%$ non-fat dry milk in TBST (100 mM Tris- $\mathrm{HCl}, \mathrm{pH} 7.5,150 \mathrm{mM}$ $\mathrm{NaCl}, 0.05 \%$ Tween-20) for $2 \mathrm{~h}$ at room temperature. The membrane was then incubated with primary antibody (rabbit polyclonal anti-Pin 1 or mouse monoclonal anti- $\beta$-catenin, diluted 1:100). The secondary antibody was used to detected bound primary antibody. Reactive protein was detected by ECL chemiluminescence system (Santa Cruz, USA) according to the manufacturer's protocol. For reblotting, membranes were stripped. Anti- $\beta$-actin (Sigma, USA) antibody served as the control.

$R T-P C R$. Briefly, total-RNAs from SACC83, ACC-2, ACC-M and SACC-LM cells were extracted from the cell monolayers using TRIzol (NEN Life Science Products, Gaithersburg, MD), according to the manufacturer's recommendations. RT-PCR was performed with Takara RNA PCR kit (AMV) Ver.3.0 (Takara). For the detection of Pin1, cyclin D1 and GAPDH mRNA, PCR primers were designed as follows, Pin1: Pin1-F, 5'-GGGAAGATGGCGGACGAGGAGAAGCTG-3'; Pin1-R, 5'-CCCTCACTCAGTGCGGAGGATGATGTG-3'. Cyclin D1: cyclin D1-F, 5'-TCGGTGTCCTACTTCAAATGTGTG-3'; cyclin D1-R, 5'-ATGGAGGGCGGATTGGAAATGA-3'. GAPDH: GAPDH-F, 5'-CACCATCTTCCAGGAGCGAG-3'; GAPDH-R, 5'-TTGCCCACAGCCTTGGCAG-3'. Amplification was performed as follows; touch-down PCR (TDPCR) was performed for the Pin1. Thermal cycling was done using the following program for TD-PCR cycles: an initial denaturation at $95^{\circ} \mathrm{C}$ for 4 min was followed by 5 cycles of TD-PCR denaturation at $94^{\circ} \mathrm{C}$ for $30 \mathrm{sec}$, annealing from 64 to $48^{\circ} \mathrm{C}$ (change of $-2^{\circ} \mathrm{C}$ per cycle) for $30 \mathrm{sec}$, and extension at $72^{\circ} \mathrm{C}$ for $30 \mathrm{sec}$, then finally $10 \mathrm{~min}$ at $72^{\circ} \mathrm{C}$ after the last cycle. The expected amplified products for Pin1, cyclin D1 and GAPDH were 501, 485, $435 \mathrm{bp}$, respectively. The products of RT-PCR were analyzed by $1 \%$ agarose gel electrophoresis.

Statistical analysis. The relationship between expressions of $ß$-catenin, Pin1 and cyclin D1 and various clinical parameters were determined by the $\chi^{2}$ test. All statistical analysis were per-formed with SPSS 11.5 software. P-value $<0.05$ was regarded as statistically significant.

\section{Results}

Immunohistochemical characterization of Pin1, cyclin D1 and $\beta$-catenin. The Pin1 polyclonal antibody showed distinct cellular staining in paraffin embedded sections of SACC clinical biopsies. In tumor cells positive for Pin1 staining, the majority of cases exhibited both nuclear and cytoplasmic accumulation of the protein at high levels. All of the normal acinar cells were negative or weak stained for Pin1, while weak to moderate Pin1 staining was also detectable in the dilatant duct near the tumor cells. In contrast, tumor cells were strongly 


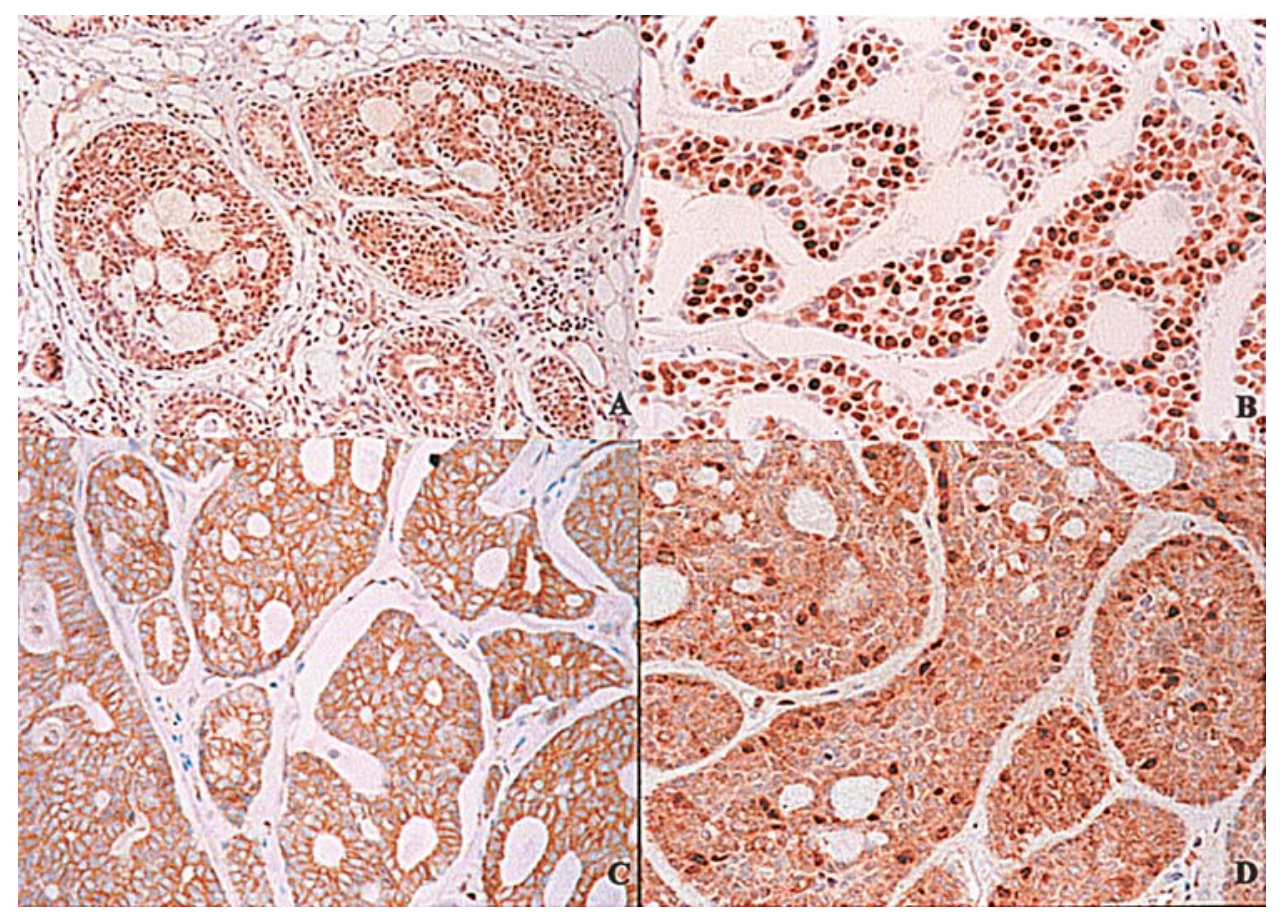

Figure 1. (A), Immunohistochemical staining of Pin1 in adenoid cystic carcinoma (original magnification x150). (B), Immunohistochemical staining of cyclin D1 in adenoid cystic carcinoma. Positive staining was granular, which localized in the nucleus (original mangification x300). (C), Immunohistochemical staining showed ubiquitous membranous expression of ß-catenin in adenoid cystic carcinoma (original magnification x300). (D), Immunohistochemical staining showed evident nuclear expression of $\beta$-catenin in adenoid cystic carcinoma (original magnification x300).

positive for the Pin1 staining, while surrounding normal connective tissue, blood vessels and stromal cells were stained negatively or only very weakly with anti-Pin 1 antibody (Fig. 1A). In the Pin 1 immunohistochemistry 3 patients (5\%) had weak staining (score 1), 11 (17\%) had moderate staining (score 2), 51 (78\%) had strong and intense staining (score 3 ). As described above, the 51 strongly and intensely staining samples (78\%) were defined as high levels of Pin1. The immunoreactivity of cyclin D1 protein staining was scored according to the percentage of positively stained tumor cell nuclei. According to previous studies, score was ranked as; negative, tumor cells were stained $<10 \%$; positive, when over $10 \%$ of tumor cells were positive (Fig. 1B). Positive immunoreactivity of cyclin D1 was observed in tumor cell nucleus of 41 specimens (63\%). Fifty-one cases (78\%) of SACC were ranked as $\beta$-catenin membrane staining, which had the localization of $\beta$-catenin primarily in the membrane (Fig. 1C). Only 14 (22\%) cases showed positive immunoreactivity for $\beta$-catenin protein in the nuclear/cytoplasmic fraction in tumor tissues, and were defined as cytoplasm/ nucleus staining, among which quite evident nuclear expression of ß-catenin was detected in 6 cases (9\%) (Fig. 1D). In addition, most of the SACC cases with metastasis (11/14) showed reduced membranous expression of $B$-catenin, three cases of which also showed cytoplasm/nucleus staining of ß-catenin in the meantime and were subsequently defined as ß-catenin nuclear/cytoplasmic staining (scored as 4). On the contrary, 15 patients without metastasis showed decreased expression of membranous $\beta$-catenin (15/51).

Association of Pin1, cyclin D1 and $\beta$-catenin with clinicopathological parameters. The relationships among Pin1,
Table II. Relationship between Pin1 and cyclin D1 protein expression in SACC.

\begin{tabular}{|c|c|c|c|c|}
\hline \multirow{2}{*}{$\begin{array}{l}\text { Cyclin D1 } \\
\text { staining }\end{array}$} & \multicolumn{4}{|c|}{ Pin1 staining } \\
\hline & $\begin{array}{c}\text { High level } \\
(\%)\end{array}$ & $\begin{array}{c}\text { Low level } \\
(\%)\end{array}$ & Total & P-value \\
\hline Positive & $36(55)$ & $5 \quad(8)$ & $41 \quad(63)$ & 0.02 \\
\hline Negative & $15(23)$ & $9(14)$ & $24 \quad(37)$ & \\
\hline Total & $51(78)$ & $14(22)$ & $65(100)$ & \\
\hline
\end{tabular}

cyclin D1 and B-catenin proteins in SACC were determined by statistical analysis. The correlation between the clinicopathologic characteristics of patients with SACC and the expression of Pin1, cyclin D1 and B-catenin in their tumors is summarised in Table I. There was no correlation between expression of Pin 1 and $\beta$-catenin, but Pin1 expression significantly correlated with cyclin D1 expression level ( $\mathrm{p}=0.02)$. Although there were no correlations between status of Pin1, ß-catenin, cyclin D1 and clinicopathological characteristics such as patients' gender, tumor stage, types and location, significant differences were found between reduced membranous expression of $\beta$-catenin and nodal metastasis in SACC $(\mathrm{p}<0.01)$, which suggested that decreased membranous expression of $\beta$ catenin associated with nodal metastasis of SACC. The results are shown in Tables II and III.

Expression of Pin1 and $\beta$-catenin at the protein level in cultured cells. We then examined the protein expression of 
Table III. Relationship between $\beta$-catenin status and nodal metastasis in SACC.

\begin{tabular}{|c|c|c|c|c|}
\hline & \multicolumn{4}{|c|}{ ß-catenin staining } \\
\hline & $\operatorname{M1}(\%)^{\mathrm{a}}$ & $\mathrm{M} 2(\%)^{\mathrm{b}}$ & Total & P-value \\
\hline No & $15(23)$ & $36(55)$ & $51 \quad(78)$ & $<0.01$ \\
\hline $\mathrm{N} 1-3$ & $11(17)$ & $3 \quad(5)$ & $14 \quad(22)$ & \\
\hline Total & $26(40)$ & $39(60)$ & $65(100)$ & \\
\hline
\end{tabular}

${ }^{\mathrm{a}} \mathrm{M} 1$, weak or even loss of membranous expression of B-catenin; ${ }^{\mathrm{b}} \mathrm{M} 2$, evident and strong membranous expression of $\beta$-catenin.

$\mathbf{A}$

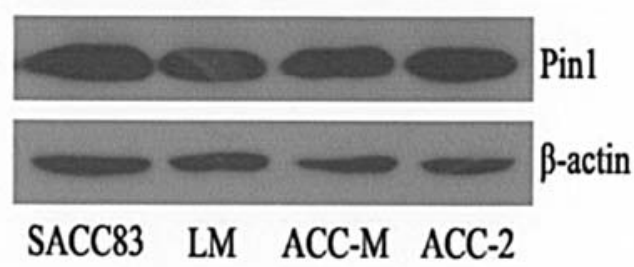

B

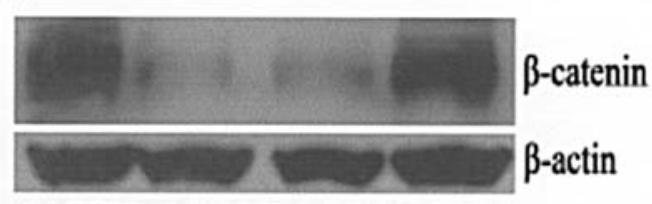

SACC83 ACC-M ACC-2 LM

Figure 2. (A), Western blot analysis of Pin1 expression in SACC83, SACCLM (LM), ACC-M and ACC-2 cell lines. The same membrane was stripped and reprobed with anti-actin antibody as a control. (B), Western blot analysis of B-catenin expression in SACC83, SACC-LM (LM), ACC-M and ACC-2 cell lines. The same membrane was stripped and reprobed with anti-actin antibody as a control.

Pin1 and B-catenin in four SACC cell lines by Western blot analysis. The results showed that the four SACC cell lines expressed Pin 1 at high levels, confirming the immunohistochemical results by also revealing overexpression of Pin1 in SACC tumor cells (Fig. 2A). Expression of B-catenin was obviously decreased in ACC-2 and ACC-M cell lines compared with its expression in SACC83 and SACC-LM cell lines, but there were no significant differences between the two highly lung metastatic salivary gland adenoid cystic carcinoma cell lines (ACC-M and SACC-LM) and their respectively homologous cell lines (ACC-2 and SACC83) (Fig. 2B).

Expression of PIN1 and cyclin DI at the mRNA level in cultured cells. To examine the expression pattern of Pin 1 in SACC cells, we analyzed the mRNA expression of Pin 1 and cyclin D1 by RT-PCR analysis in four SACC cell lines. The results showed that levels of mRNA expression were equivalent to levels of Pin 1 and cyclin D1 protein expression in the four cell lines (Fig. 3).
A

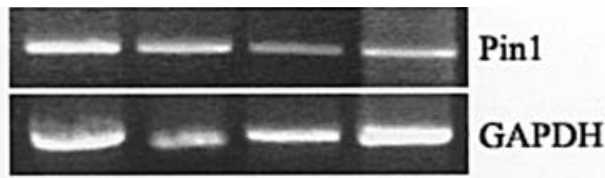

B

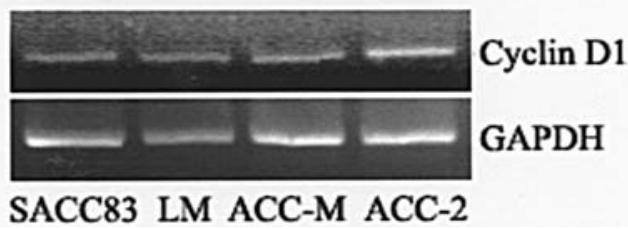

Figure 3. (A), RT-PCR analysis of Pin1 mRNA expression in SACC83, SACC-LM (LM), ACC-M and ACC-2 cell lines; GAPDH as a control. (B), RT-PCR analysis of cyclin D1 mRNA expression in SACC83, SACC-LM (LM), ACC-M and ACC-2 cell lines; GAPDH as a control.

\section{Discussion}

Salivary adenoid cystic carcinoma is a slow-growing tumor but highly malignant neoplasm with extremely poor long-term prognosis and often late local recurrences after surgical resection, even following radiotherapy. Daa et al reported that mutations in components of the Wnt signaling pathway, such as the CTNNB1, APC and AXIN1 genes, were quite common in salivary adenoid cystic carcinoma, suggesting that abnormalities in the Wnt signaling pathway might play a role in the tumorigenesis and growth of salivary adenoid cystic carcinoma (17).

Wnt signaling pathway is not only crucial to embryonic development but also pivotal in tumorigenesis. By stimulating the transcriptional activities of DNA-binding proteins in the TCF/LEF-1 family, the Wnt signaling cascade is able to control cell behavior $(18,19)$. The target genes of Wnt signaling include genes for proteins that drive the cell cycle and growth factors such as cyclin D1 and c-Myc (20). Since ß-catenin stimulates cell proliferation by stimulating the transcriptional activity of members of the TCF/LEF-1 family, inappropriately accumulated $B$-catenin acts similar to the product of an oncogene (21). In our study, we detected strong cytoplasmic expression of B-catenin in 14 cases of SACC (21\%), among which quite evident nuclear expression of $\beta$-catenin was detected in 6 cases $(9 \%)$ by immunohistochemistry. However, our negative immunohistochemical results do not eliminate the possibility of nuclear localization of B-catenin because weak nuclear staining was difficult to evaluate, as noted above. Unlike the results found by Frierson et al that there was no nuclear immunoreactivity specific for $\beta$-catenin in adenoid cystic carcinomas, the results of our immunohistochemical staining showed that nuclear expression of B-catenin was evident in some cases (22). This nuclear expression of $\beta$-catenin can be regarded as an indication for activated, oncogenic, Wnt signalling and $ß$-catenin/TCF transcription. Previous studies suggest activated Wnt signalling in tumors is caused by increased levels of $B$-catenin, which can be the result of mutations in APC, B-catenin, AXIN1, AXIN2 or B-TrCP (23-29). Activated Wnt signaling can also be the result of activation of the canonical Wnt pathway by secreted Wnts or by expression of the Wnt receptors Frizzled proteins and lipoprotein receptor-related proteins 5 and 6 (LRP-5/6) (30-32). We intend to analyze the mutations of CTNNB1, APC, 
AXIN1 and LRP6 genes in our SACC samples and cell lines to predict the mechanism of aberrant $\beta$-catenin nuclear expression. In addition, we found reduced membranous expression of $\beta$-catenin in most of the patients with metastasis $(11 / 14,79 \%)$, three cases of which showed B-catenin cytoplasm/ nucleus staining in the meantime and were subsequently defined as $\beta$-catenin nuclear/cytoplasmic staining (scored as 4). On the contrary, only 15 (29\%) of the 51 cases of SACC without metastasis showed decreased membranous expres-sion of $\beta$-catenin. There was a significant correlation between reduced membranous expression of $\beta-$ catenin and nodal metastasis in SACC $(\mathrm{p}<0.01)$. To our knowledge, in addition to its function in the Wnt signaling pathway, B-catenin also binds tightly to the cytoplasmic domain of type I cadherins and plays an essential role in the structural organization and function of cadherins by linking cadherins through $\alpha$-catenin to the actin cytoskeleton in cellcell adhesion. So, the reduced membranous expression of $\beta-$ catenin might affect its function in cell-cell adhesion, and subsequently result in metastasis of tumor cells. Our result of Western blotting showed B-catenin expression increased evidently in SACC83 and SACC-LM cell lines comparing with its expression in ACC-2 and ACC-M cell lines, indicating activated Wnt signaling in SACC83 and SACCLM cell lines. The exact reason was unclear as the causes for increased levels of $\beta$-catenin were complex. Since ACC-2 and ACC-M cell lines express B-catenin at very low level, in future work we can tranduce $B$-catenin complementary DNA (cDNA) into these two cell lines to study the roles of $B-$ catenin in carcinogenesis of SACC. No significant difference was found in $B$-catenin expression between the two highly lung metastatic salivary gland adenoid cystic carcinoma cell lines (ACC-M and SACC-LM) and their respectively homologous cell lines (ACC-2 and SACC83). Considering that we detected $\beta$-catenin expression in the whole-cell extrat not membrane fraction and our result of immunohistochemical staining showed that $\beta$-catenin cytoplasmic/ nuclearic expression increased in the tumor cells in some cases, we then extracted cytoplasm/nuclei fraction from the whole-cell of SACC cell lines and examined B-catenin protein expression in them. The result showed that cytoplasmic/ nuclearic expression of $B$-catenin was significantly higher in SACC cell lines than in SACC-LM, which in turn indicated membranous expression of $B$-catenin reduced in the highly metastatic SACC cell lines (data not shown).

Pin 1 is a peptidyl-prolyl cis-trans isomerase (PPIase) that isomerizes only phosphorylated serine/threonine residues preceding proline peptide bonds in a defined subset of proteins, thereby affecting their functions. Recent studies indicate that phosphorylation-specific prolyl isomerizaton is a novel postphosphorylation regulatory mechanism inducing conformational changes following phosphorylation to control protein function, and this new regulatory mechanism is pivotal in regulating cellular functions, offering new insights into the pathogenesis and treatment of cancer (33-34). Pin1 specifically binds to the pSer246-Pro motif of ß-catenin and inhibits its binding to APC, resulting in the nuclear accumulation and stabilization of $B$-catenin (35). It has been shown that Pin1 is strikingly overexpressed in breast cancer, hepatocellular carcinoma and oral squamous cell carcinoma, and that its over- expression leads to the up-regulation of cyclin D1 and transformation of breast epithelial cells and hepatocytes (36,37). Importantly, Pin 1 positively regulates the function of cyclin D1 at the transcriptional level and through post-translational stabilization. Indeed, in the mouse, Pin 1 knockout reduces cyclin D1 levels and results in phenotypes resembling those of cyclin D1-null mice (38). Furthermore, inhibition of Pin1 suppresses the Neu- and Ras-induced transformed phenotypes, which can be fully rescued by overexpression of a constitutively active cyclin D1 mutant that is refractory to the Pin1 inhibition (39). These results indicate that Pin1 may be an important factor in regulating cyclin D1 expression in carcinogenesis. In this study, we found Pin1 was strikingly overexpressed in that majority of 51 SACC cases $(78 \%)$ exhibiting both nuclear and cytoplasmic accumulation of the protein at high levels, while all of the normal acinar cells were negative stained for Pin1. Furthermore, high Pin1 levels significantly correlated with cycinD1 overexpression $(\mathrm{p}=0.02)$. Western blotting confirmed the immunohistochemical results by also revealing overexpression of Pin1 in SACC tumor cells, and levels of mRNA expression were equivalent to levels of Pin1 and cyclin D1 protein expression in all four SACC cell lines.

In conclusion, our results showed that Pin1 was overexpressed in SACC, and high levels of Pin1 expression correlated with cyclin D1 expression; moreover, we detected cytoplasmic accumulation and evident nuclear expressions of $\beta$-catenin in some tumor cells, as well as significantly reduced membranous expression of $\beta$-catenin was found in most of the metastatic SACC, which suggest that Pin1 and Wnt signalling pathways are activated in SACC and may play a pivotal role in carcinogenesis and metastasis of SACC.

\section{Acknowledgements}

This research was supported by the Research Grant from National Nature Science Foundation of P.R. China (30471894).

\section{References}

1. Ellis GL and Auclair PL: Adenoid cystic carcinoma. In: Atlas of Tumor Pathology. Third Series, Fascicle 17. Tumors of the Salivary Glands. Armed Forces Institute of Pathology, Washington, DC, pp203-216, 1996.

2. Wodarz A and Nusse R: Mechanisms of Wnt signaling in development. Annu Rev Cell Dev Biol 14: 59-88, 1998.

3. Behrens J, von Kries JP, Kuhl M, et al: Fuctional interaction of beta-catenin with the transcription factor LEF-1. Nature 382: 638-642, 1996.

4. Shutman M, Zhurinsky J, Simcha I, et al: The cyclin D1 gene is a target of the beta-catenin/LEF-1 pathway. Proc Natl Acad Sci USA 96: 5522-5527, 1999.

5. Fodde R, Smits R and Clevers H: APC, signal transduction and genetic instability in colorectal cancer. Nat Rev Cancer 1: 55-67, 2001.

6. Tsuchiya R, Yamamoto G, Nagochi Y, Aida T, Irie T and Tachikawa T: Expression of adenomatous polyposis coli (APC) in tumorigenesis of human oral squamous cell carcinoma. Oral Oncol 40: 932-940, 2004.

7. Neufeld KL, Zhang F, Cullen BR and White RL: APC-mediated down-regulation of $B$-catenin activity involves nuclear sequestration and nuclear export. EMBO Rep 1: 519-523, 2000.

8. Fujimori M, Ikeda S, Shimizu Y, Okajima M and Asahara T: Accumulation of $\beta$-catenin protein and mutations in exon 3 of B-catenin gene in gastrointestinal carcinoid tumor. Cancer Res 61: 6656-6659, 2001. 
9. Koch A, Waha A, Tonn JC, et al: Somatic mutations of WNT/ wingless signaling pathway components in primitive neuroectodermal tumors. Int J Cancer 93: 445-449, 2001.

10. Moon RT, Bowerman B, Boutros M and Perrimon N: The promise and perils of Wnt signaling through beta-catenin. Science 296: 1644-1646, 2002.

11. Lin SY, Xia W, Wang JC, et al: Beta-catenin, a novel prognostic marker for breast cancer:its roles in cyclin D1 expression and cancer progression. Proc Natl Acad Sci USA 97: 4262-4266, 2000.

12. Wulf GM, Ryo A, Wulf GG, et al: Pin1 is overexpressed in breast cancer and potentistes the transcriptional activity of phosphorylated c-Jun towards the cyclin D1 gene. EMBO J 20: 3459-3472, 2001

13. Ryo A, Liou YC, Lu KP and Wulf G: Prolyl isomerase Pin1: a catalyst for oncogenesis and a potential therapeutic target in cancer. J Cell Sci 116: 773-783, 2003.

14. Ayala G, Wang D, Wulf G, et al: Pin1 is a novel prognostic marker in prostate cancer. Cancer Res 63: 6244-6251, 2003.

15. Pang R, John Y, Yuen MF, et al: Pin1 overexpression and Bcatenin gene mutation are distinct oncogene events in human hepatocellular carcinoma. Oncogene 23: 4182-4186, 2004.

16. Ryo A, Nakamura M, Wulf G, Liou YC and Lu KP: Pin1 regulates turnover and subcellular localization of beta-catenin by inhibiting its interaction with APC. Nat Cell Biol 3: 793-801, 2001.

17. Daa T, Kashima K, Kaku N, Suzaki M and Yokoyama S: Mutations in components of the Wnt signaling pathway in adenoid cystic carcinoma. Modern Pathol 17: 1475-1482, 2004.

18. Barker $\mathrm{N}$ and Clevers $\mathrm{H}$ : Catenins, Wnt signaling and cancer. Bioessays 22: 961-965, 2000.

19. Peifer M and Polakis P: Wnt signaling in oncogenesis and embryogenesis - a look outside the nucleus. Science 287: 1606-1609, 2000.

20. He TC, Sparks AB, Rago C, et al: Identification of c-MYC as a target of the APC Pathway. Science 281: 1509-1512, 1998.

21. Moreno-Bueno G, Hardisson D, Sanchez C, et al: Abnormalities of the APC/beta-catenin pathway in endometrial cancer. Oncogene 21: 7981-7990, 2002.

22. Frierson HF Jr, El-Naggar AK, Welsh JB, et al: Large scale molecular analysis identifies genes with altered expression in salivary adenoid cystic carcinoma. Am J Pathol 161: 1315-1323, 2002.

23. Huang J, Papadopoulos N, Mckinley AJ, et al: APC mutations in colorectal tumors with mismatch repair deficiency. Proc Natl Acad Sci USA 93: 9049-9054, 1996.

24. Bienz $M$ and Clevers H: Linking colorectal cancer to Wnt signaling. Cell 103: 311-320, 2000.
25. Liu W, Dong X, Mai M, et al: Mutations in AXIN2 cause colorectal cancer with defective mismatch repair by activating betacatenin/TCF signalling. Nat Genet 26: 146-147, 2000.

26. Gerstein AV, Almeida TA, Zhao G, et al: APC/CTNNB1 (betacatenin) pathway alterations in human prostate cancers. Genes Chromosomes Cancer 34: 9-16, 2002.

27. Hajra KM and Fearon ER: Cadherin and catenin alterations in human cancer. Genes Chromosomes Cancer 34: 255-268, 2002.

28. Taniguchi K, Roberts LR, Aderca IN, et al: Mutational spectrum of beta-catenin, AXIN1 and AXIN2 in hepatocellular carcinomas and hepatoblastomas. Oncogene 21: 4863-4871, 2002.

29. Yokota N, Nishizawa S, Ohta S, et al: Role of Wnt pathway in medulloblastoma oncogenesis. Int J Cancer 101: 198-201, 2002.

30. Mizushima T, Nakagawa H, Kamberov YG, Wilder EL, Klein PS and Rustgi AK: Wnt-1 but not epidermal growth factor induces beta-catenin/T-cell factor-dependent transcription in esophageal cancer cells. Cancer Res 62: 277-282, 2002.

31. Wang Z, Shu W, Lu MM and Morrisey EE: Wnt7b activates canonical signaling in epithelial and vascular smooth muscle cells through interactions with Fzd1, Fzd10 and LRP5. Mol Cell Biol 25: 5022-5030, 2005.

32. Mi K and Johnson GV: Role of the intracellular domains of LRP5 and LRP6 in activating the Wnt canonical pathway. Cell Biochem 95: 328-338, 2005.

33. Winkler KE, Swenson KI, Kornbluth S and Means AR: Requirement of the prolyl isomerase Pin 1 for the replication check-point. Science 287: 1644-1647, 2000

34. Yaffe MB, Schutkowski M, Shen M, et al: Sequence-specific and phosphorylation-dependent praline isomerization: a potential mitotic regulatory mechanism. Science 278: 1957-1960, 1997.

35. Miyashita H, Mori S, Motegi K, Fukumoto M and Uchida T: Pin1 is overexpressed in oral squamous cell carcinoma and its levels correlate with cyclin D1 overexpression. Oncol Rep 10: 455-461, 2003.

36. Wulf G, Garg P, Liou YC, Iglehart D and Lu KP: Modeling breast cancer in vivo and ex vivo reveals an essential role of Pin 1 in tumorigenesis. EMBO J 23: 3397-3407, 2004.

37. Bao L, Kimzey A, Sauter G, Sowadski JM, Lu KP and Wang DG: Prevalent overexpression of prolyl isomerase Pin 1 in human cancers. Am J Pathol 164: 1727-1737, 2004.

38. Liou YC, Ryo A, Huang HK, et al: Loss of Pin1 function in the mouse causes phenotypes resembling cyclin D1-null phenotypes. Proc Natl Acad Sci USA 99: 1335-1340, 2002.

39. Ryo A, Liou YC, Wulf G, Nakamura M, Lee SW and Lu KP: Pin1 is an E3F target gene essential for the Neu/Ras-induced transformation of mammary epithelial cells. Mol Cell Biol 22: 5281-5295, 2002. 